\title{
Analysis of Correlation between the Seven Important Helicobacter pylori (H. pylori) Virulence Factors and Drug Resistance in Patients with Gastritis
}

\author{
Sinem Oktem-Okullu ${ }^{10},{ }^{1}$ Zehra Cekic-Kipritci, ${ }^{2}$ Elif Kilic, ${ }^{3}$ Nogayhan Seymen, \\ Nesteren Mansur-Ozen, ${ }^{3}$ Ugur Sezerman, ${ }^{5}$ and Yesim Gurol ${ }^{1}$ \\ ${ }^{1}$ Department of Medical Microbiology, Acibadem Mehmet Ali Aydinlar University, School of Medicine, Atasehir, Istanbul, Turkey \\ ${ }^{2}$ Yeditepe University Hospital, Istanbul, Turkey \\ ${ }^{3}$ Department of Medical Biotechnology, Acibadem Mehmet Ali Aydinlar University, Institute of Health and Science, Atasehir, \\ Istanbul, Turkey \\ ${ }^{4}$ Department of Biostatistics and Bioinformatics, Acibadem Mehmet Ali Aydinlar University, Institute of Health and Science, \\ Atasehir, Istanbul, Turkey \\ ${ }^{5}$ Department of Biostatistics and Medical Informatics, Acibadem Mehmet Ali Aydinlar University, School of Medicine, Atasehir, \\ Istanbul, Turkey
}

Correspondence should be addressed to Sinem Oktem-Okullu; sinem.oktem@acibadem.edu.tr

Received 11 July 2020; Revised 7 August 2020; Accepted 8 August 2020; Published 29 August 2020

Academic Editor: Amosy M'Koma

Copyright (C) 2020 Sinem Oktem-Okullu et al. This is an open access article distributed under the Creative Commons Attribution License, which permits unrestricted use, distribution, and reproduction in any medium, provided the original work is properly cited.

\begin{abstract}
The aim of this study is to evaluate the association between seven important $H$. pylori virulence factors and antibiotic resistance in patients with gastritis. H. pylori strains isolated from 33 patients with gastritis were examined. Antimicrobial susceptibilities were tested by GenoType ${ }^{\circledR}$ HelicoDR (Hain Life Science, Germany) test kit and RT-PCR. The virulence-factors were determined using conventional PCR. 39\% of patients were resistant for clarithromycin and $27 \%$ of patients were resistant for fluoroquinolone. $15 \%$ of patients were resistant to both clarithromycin and fluoroquinolone. The $H$. pylori vacA $\mathrm{m} 1 / \mathrm{s} 2$ genotype was the most frequent allelic combination. Patients were possessed the vacA s1, $m 1$ (6.1\%); s1, $m 2$ (6.1\%); s2, $m 1$ (15.1\%); and $s 2, m 2$ (3.0\%) genotypes. $94 \%$ of patients with gastritis were positive for $H$. pylori napA gene. Also, there were no dupA gene-positive gastritis patients. There was no significant correlation between the vacA, cagA, oipA, $h p a A, b a b A$, napA, dupA, ureA, ureB virulence genes, clarithromycin, and fluoroquinolone resistance. Herein, we report that the relationship between the $H$. pylori napA gene and gastritis. Although we found a correlation between $H$. pylori virulence factor and clinical outcome, there is a need for further studies to enlighten the relation between $H$. pylori virulence genes and antibiotic resistance.
\end{abstract}

\section{Introduction}

Helicobacter pylori (H. pylori) is one of the most important human pathogenic microorganisms with its spiral shape that can endure asymptomatic or can cause several gastrointestinal diseases, ranging in acute and chronic gastritis, gastric and duodenal ulcers, gastric adenocarcinoma, and MALT (mucosa-associated lymphoid tissue) lymphoma [1]. The prevalence rate of $H$. pylori differs between the developed countries that have low prevalence and developing countries that have a high prevalence. $H$. pylori infection is usually gained during childhood and if it is not treated, it will continue to lifespan [2].

For the treatment of $H$. pylori, multiple antibiotic regimens have been evaluated including triple therapy, sequential therapy, quadruple therapy, and levofloxacin-based triple therapy. Antimicrobial susceptibility testing is the best approach to choosing the treatment therapy method. Besides 
this eradication rates, previous antibiotic exposure and regional antibiotic-resistance patterns should be considered for successful treatment.

In the first-line treatment, a triple therapy regimen is applied including usually a proton pump inhibitor (PPI) combined with clarithromycin and amoxicillin or metronidazole as an antibiotic [3]. Clarithromycin-based therapies were considered to be the best tolerated and safest therapies; However, the efficacy of these triple regimens has decreased due to bacterial resistance to antibiotics [4]. To overcome antimicrobial resistance seen in $H$. pylori treatment, new antibiotics and different drug combinations have been evaluated, using fluoroquinolones, rifabutin, furazolidone, and azithromycin 14-day levofloxacin or 5-day levofloxacin concomitant therapy could be an alternative fluoroquinolone therapy regimes where fluoroquinolone resistance is rare [5].

As a highly heterogeneous bacterium virulence of $H$. pylori varies geographically. Due to the research in the literature, it is clearly explained that $H$. pylori virulence factors have a very important effect on both bacterial pathogenicity and treatment outcome [6].

Vacuolating cytotoxin gene A (vacA), cytotoxin-associated gene $\mathrm{A}(\operatorname{cag} A)$, outer inflammatory protein A (oipA), the blood group antigen-binding adhesin gene $\mathrm{A}(b a b A)$, neutrophilactivating protein $\mathrm{A}(n a p A)$, the putative neuraminyllactosebinding hemagglutinin homolog $(h p a A)$, duodenal ulcer promoting gene $\mathrm{A}(\operatorname{dup} A)$, urease $\mathrm{A}$ (ure $\mathrm{A})$, and urease $\mathrm{B}$ (ureB) are the most important virulence genes of this bacterium that take the role in the invasion, adhesion, and colonization of $H$. pylori strains in gastric epithelial cells $[7,8]$.

The present study is aimed at assessing the relationship between clarithromycin and fluoroquinolone resistance with the seven important $H$. pylori virulence factor status.

\section{Material and Methods}

2.1. Ethical Approval. A written informed consent about the participation in this study was provided to each patient included in this study. The ethical committee of Yeditepe University approved this study.

2.2. Patient Selection. 33 patients were included in the study who underwent endoscopy because of gastroduodenal diseases at the Gastroenterology Department of Yeditepe University, in Istanbul, Turkey. They were selected due to the who fulfilled the obtaining expulsion criteria.

2.3. Gastric Biopsy Specimens. Gastric biopsy specimens of the patients were taken from the antrum part of the stomach. Freshly taken biopsy specimens were placed into the Nucliswab $^{\circledR}$ Solution (Salubris, USA) and kept at $+4^{\circ} \mathrm{C}$ for overnight, then put at $-80^{\circ} \mathrm{C}$ deep freezer until DNA isolation.

2.4. DNA Isolation. To study virulence factors of $H$. pylori, DNA was extracted by using QIAamp DNA mini DNA isolation kit (Qiagen, Hilden, Germany)) following the manufacturer's description. All DNA samples were quantified using NanoDrop (ND-2000, THERMO) and maintained in $-80^{\circ} \mathrm{C}$ deep freezer.
2.5. Antimicrobial Susceptibility Testing. Fluoroquinolone and clarithromycin resistance were tested by using GenoType $^{\circledR}$ HelicoDR(Hain Life Science, Germany) test kit as described by the following the manufacturer's description. The point mutations related to the clarithromycin resistance was detected by using a real-time PCR- (RT-PCR-) based hybridization assay. $H$. pylori $23 \mathrm{SrRNA}$ gene-specific primers with probes shown in Table 1 were used, and melting curve analysis was done. For the RT-PCR experiments and hybridization reactions, LightCycler thermocycler (Roche Diagnostics, Neuilly Sur Seine, France) was used.

Real-time PCR reactions were done by using glass capillary tubes with $20 \mu \mathrm{l}$ volume. $3 \mu \mathrm{l}$ template DNA, $0.4 \mu \mathrm{l}$ forward and reverse primers $(20 \mu \mathrm{M}$ each $), 0.2 \mu \mathrm{l}$ sensor and anchor probes $(20 \mu \mathrm{M}$ each), and $2 \mu \mathrm{l}$ of FastStart DNA Master Hybridization Probes (Roche Diagnostics) were included into each tube. The RT-PCR reaction conditions were $95^{\circ} \mathrm{C}$ for $10 \mathrm{~min}$ as an initial denaturation, $95^{\circ} \mathrm{C}$ for $0 \mathrm{~s}$ for 50 amplification cycles, $60^{\circ} \mathrm{C}$ for $10 \mathrm{~s}$ as annealing, and $72^{\circ} \mathrm{C}$ for $17 \mathrm{~s}$ as an extension. Also, a melting curve step was added to the reaction composed of $95^{\circ} \mathrm{C}$ for $0 \mathrm{~s}, 45^{\circ} \mathrm{C}$ for $30 \mathrm{~s}$ to cool (temperature transition rate of $20^{\circ} \mathrm{C} / \mathrm{s}$ ), and in the final step, a slow increase in the temperature to $85^{\circ} \mathrm{C}$ at a rate of $0.1^{\circ} \mathrm{C} / \mathrm{s}$ with the continuous acquisition of fluorescence decrease [11].

2.6. Virulence Factor Testing. Extracted patients' DNA samples were used as a template DNA in PCR to detect virulence factors of $H$. pylori which are vacA, cagA, oipA, hpaA, babA, $n a p A, \operatorname{dup} A, u r e A$, and $u r e B$ genes. The primer sequences and the size of PCR products used in this study were summarized in Table 2. Genomic DNA of H. pylori isolated from the H. pylori G27 strain was used as a positive control DNA for PCR assay. Negative control was used by replacing templated DNA with distilled water. Each PCR amplification was carried out in a volume of $15 \mu \mathrm{l}$ containing $3 \mu \mathrm{l}$ of $5 \mathrm{X}$ Dye Hot Start Master Mix (GeneMark Bio, TAİWAN), $10 \mu \mathrm{M}$ of forward and reverse primers, and $3 \mu \mathrm{l}$ of templated DNA. The remaining volume was adjusted with distilled water Different amplification mixtures were prepared using primer pairs belonging to each virulence factor. Each PCR set was included in the negative and positive controls. Conventional PCR reaction conditions were initial denaturation 3 minutes at $95^{\circ} \mathrm{C}, 40$ cycles of denaturation 30 seconds at $95^{\circ} \mathrm{C}$, annealing 45 second at $60^{\circ} \mathrm{C}$ and extension 1 minute at $72^{\circ} \mathrm{C}$, and final extension 5 minutes at $72^{\circ} \mathrm{C}$. Only for oipA gene, annealing temperature was used as $59.2^{\circ} \mathrm{C}$ instead of $60^{\circ} \mathrm{C}$. PCR amplifications were performed in a thermal cycler (Bio-Rad T100).

$7 \mu \mathrm{l}$ of PCR products was loaded to agarose gel electrophoresis in 1\% agarose gel in 1X Tris Acetic Acid Edta (TAE) buffer at $100 \mathrm{~V}$ for $60 \mathrm{~min}$ and stained with ethidium bromide. Then, the agarose gels were visualized by the gel imaging system (ChemiDoc ${ }^{\mathrm{TM}}$ MP imaging system, Bio-Rad).

2.7. Statistical and Bioinformatic Analyses. Our data consists of the presence of virulence factors (cagA, ureA, ureB, napA, hpaA, oipA, and dupA) and drug resistances (clarithromycin resistance and fluoroquinolone resistance), all binary values 
TABLe 1: Real-time PCR primers and probe sequence.

\begin{tabular}{|c|c|c|c|c|}
\hline Virulence factor & Primer name & Primer sequences $\left(5^{\prime}-3^{\prime}\right)$ & Product size (bp) & Reference \\
\hline \multirow{4}{*}{ 23SrRNA } & HPYS/F & TATGGTACCCGCATGATATTCCCATTAGCAGT & \multirow{2}{*}{267} & {$[9,10]$} \\
\hline & HPYA/R & TAAGAGCTCAGGTTAAGAGGATGCGTCAGTC & & {$[9,10]$} \\
\hline & $\begin{array}{l}\text { Sensor probe } 5^{\prime} \text { labeled } \\
\text { with LC-red } 640\end{array}$ & GGCAAGACGGAAAGACC & 2504 to 2520 & {$[9,10]$} \\
\hline & $\begin{array}{c}\text { Anchor probe } 3^{\prime} \text { labeled } \\
\text { with fluorescein }\end{array}$ & TGTAGTGGAGGTGAAAATTCCTCCTACCC & 2473 to 2501 & {$[9,10]$} \\
\hline
\end{tabular}

TABLe 2: H. pylori virulence factor primer sequences used in the study.

\begin{tabular}{|c|c|c|c|c|}
\hline Virulence factor & Primer name & Primer sequences $\left(5^{\prime}-3^{\prime}\right)$ & Product size (bp) & Reference \\
\hline \multirow{2}{*}{ ureA } & ure $\mathrm{A} / \mathrm{F}$ & TGATGGGACCAACTCGTAACCGT & \multirow{2}{*}{244} & \multirow{2}{*}[12]{} \\
\hline & ure $A / R$ & CGCAATGTCTAAGCGTTTGCCGAA & & \\
\hline \multirow{2}{*}{ ureB } & ure $\mathrm{B} / \mathrm{F}$ & AGTAGCCCGGTGAACACAACATCCT & \multirow{2}{*}{645} & \multirow{2}{*}[12]{} \\
\hline & ure $B / R$ & ATGCCTTTGTCATAAGCCGCTTGG & & \\
\hline \multirow{2}{*}{ napA } & nap A/F & GAATGTGAAAGGCACCGATT & \multirow{2}{*}{304} & \multirow{2}{*}[12]{} \\
\hline & nap $A / R$ & ATCGTCCGCATAAGTTACGG & & \\
\hline \multirow{2}{*}{$b a b A$} & $\mathrm{bab} \mathrm{A} / \mathrm{F}$ & AATCCAAAAAGGAGAAAAAGTATGAAA & \multirow{2}{*}{$832 / 601$} & \multirow{2}{*}[12]{} \\
\hline & $\mathrm{bab} \mathrm{A} / \mathrm{R}$ & TGTTAGTGATTTCGGTGTAGGACA & & \\
\hline \multirow{2}{*}{ dupA } & $\operatorname{dup} \mathrm{A} / \mathrm{F}$ & TGAGCGTGGTAGCTCTTGAC & \multirow{2}{*}{584} & \multirow{2}{*}[12]{} \\
\hline & $\operatorname{dup} A / R$ & GAGCGCGTTAGCGATATAGG & & \\
\hline \multirow{2}{*}{ hpaA } & hpa A/F & TAGTGGGATGCAGCCCGCATATTA & \multirow{2}{*}{534} & \multirow{2}{*}[12]{} \\
\hline & hpa A/R & CGCTATGGCTTGAATGGGTGGTTT & & \\
\hline \multirow{2}{*}{ oipA } & oip A/F & CATTAAGCGGTGGTTTTGTG & \multirow{2}{*}{1093} & \multirow{2}{*}{ This study } \\
\hline & oip A/R & AGCCAACTAAAGAGCGGTAA & & \\
\hline \multirow{2}{*}{$\operatorname{cag} A$} & cagA/F & GTTGATAACGCTGTCGCTTC & \multirow{2}{*}{350} & \multirow{2}{*}{ [13] } \\
\hline & $\operatorname{cag} A / R$ & GGGTTGTATGATATTTTCCATAA & & \\
\hline \multirow{2}{*}{$\operatorname{VacA} s 1 / s 2$} & $\mathrm{VAI} / \mathrm{F}$ & ATGGAAATACAACAAACACAC & \multirow{2}{*}{$259 / 286$} & \multirow{2}{*}[14]{} \\
\hline & $\mathrm{VAI} / \mathrm{R}$ & CTGCTTGAATGCGCCAAAC & & \\
\hline \multirow{2}{*}{ VacA $m 1 / m 2$} & VAG/F & CAATCTGTCCAATCAAGCGAG & \multirow{2}{*}{$567 / 642$} & \multirow{2}{*}{ [14] } \\
\hline & VAG/R & GCGTCAAAATAATTCCAAGG & & \\
\hline \multirow{2}{*}{ 16S rRNA } & rRNA/F & TAAGAGATCAGCCTATGTCC & \multirow{2}{*}{534} & \multirow{2}{*}{ [15] } \\
\hline & rRNA/R & TCCCACGCTTTAAGCGCAAT & & \\
\hline
\end{tabular}

depicting absence/presence, WT/MUT, and resistant/susceptible, respectively. There is a total of $33 \mathrm{H}$. pylori-positive samples with a mean age of 37.3. Since none of the patients have dupA, that virulence factor was excluded from the study as there will be no meaningful comparison.

For the creation of the correlation tables, we have used Pearson's correlation and performed all analysis in Python, scipy v1.0.0. To observe meaningful differences in outcomes, we performed two-proportion $z$-test. Two-proportion $z$-test was the test of choice here as the sample size is quite small and this test better reflects proportional differences in different sample groups. An alpha value less than or equal to 0.05 was considered significant for both the Pearson and twoproportion $z$-tests.

Our initial tests showed no significant difference in the occurrence of the $H$. pylori virulence factors between clari- thromycin and fluoroquinolone susceptible/resistance samples. We, therefore, tried a combinatorial approach where we performed the same tests with coupled virulence factors. If both given virulence factors were not present in a patient-for example, both VacA $\mathrm{ml}$ and OipA are absentthen, the new combined feature VacA m1/OipA will also be absent. However, if any or both are present in that patient, then the new feature will be present. In addition to expanding our search space, this also enabled us to check whether these virulence factors occur in tandem or not.

After two proportions of $z$-tests, we have observed a significant difference in combined VacA $m 1$ and VacA s2 ( $p$ value $=0.03$ ) between patients susceptible/resistant to clarithromycin. While VacA_m1/VacA_s2 is present in $55 \%(11 / 20)$ of susceptible patients, it is present in only $23.1 \%(3 / 13)$ of resistant patients. 


\section{Results}

3.1. Antibiotic Resistance. Due to the antibiotic resistance test results, 39\% of patients were resistant for clarithromycin and $27 \%$ of patients were resistant for fluoroquinolone. $15 \%$ of patients were resistant to both clarithromycin and fluoroquinolone. Resistance rates were shown in Table 3.

3.2. Association between Virulence Genotypes and Gastritis. According to the conventional PCR results which were performed using 33 patients with gastritis, virulence gene distributions are shown in Table 4. H. pylori ure $A$ and ureB gene amplification were found in $73 \%$ and $24 \%$ of all isolates, respectively. $H$. pylori vacA $s 2 / m 1$ (15.1\%) genotypes were detected as the most frequent allelic combination of the vacA gene among gastritis patients followed by vacA $s 1, m 1$ (6.1\%); $s 1, m 2$ (6.1\%); and $s 2, m 2(3.0 \%)$ genotypes. $94 \%$ of patients with gastritis were positive for $H$. pylori napA gene. Additionally, no gastritis patients were positive for $d u p A$ gene.

\subsection{Correlation between Antibiotic Resistance and Virulence} Factor Genotype. The relation between the clarithromycin and fluoroquinolone resistance with $H$. pylori virulence genes was evaluated (Tables 5 and 6). Due to our data results, there was no significant correlation between the vacA, cagA, oipA, hраA, babA, парA, dupA, ure $A$, ure $B$ virulence genes, and clarithromycin, and fluoroquinolone resistance. However, our data showed that there was a significant relationship between vac A s1/m2 allelic variation and clarithromycin susceptibility ( $p$ value $<0.05$ ).

\section{Discussion}

Helicobacter pylori is a common pathogenic bacteria colonizer of the human stomach, and the bacteria have an essential role in the development of different gastroduodenal diseases including gastritis, peptic ulcers, and gastric cancer. Approximately, half of the world's population has been presumed to be infected with this pathogenic bacterium, but only a small amount of infected people develop gastroduodenal diseases. H. pylori is a highly heterogeneous bacterium, and bacterial virulence genes play a pivotal role in determining the clinical outcome of $H$. pylori infection. For the treatment of $H$. pylori infection, different types of antibiotic therapy are applied to patients. However, similar to other bacterial infections, drug resistance is the most important cause of eradication failure for this bacterium. Different factors could affect $H$. pylori drug resistance. Age and gender, socioeconomic status, host disease status, and virulence factors of the pathogens are the most important factors that influence $H$. pylori drug resistance [16].

Clarithromycin and fluoroquinolones are important drugs for the treatment of $H$. pylori infection and resistance to these drugs has been associated with eradication failure. In this present study, it was aimed at evaluating the association between seven important $H$. pylori virulence genes, vacA, cagA, oipA, hpaA, babA, napA, dupA, ure A, and ureB, with the clarithromycin and fluoroquinolone resistance in H. pylori-infected patients with gastritis. Due to the PCR results $H$. pylori ure $A$ and $u r e B$ virulence gene amplification
TABLE 3: Antibiotic resistance rates of patients with gastritis.

\begin{tabular}{lc}
\hline Drug resistance & $\begin{array}{c}\text { Patient number and } \\
\text { percentage, } n(\%)\end{array}$ \\
\hline Clarithromycin resistance & $13(39)$ \\
$\begin{array}{l}\text { Fluoroquinolone resistance } \\
\text { Clarithromycin and fluoroquinolone } \\
\text { resistance }\end{array}$ & $9(27)$ \\
\hline
\end{tabular}

TABle 4: Correlation between presence or absence of $H$. pylori virulence genes and gastritis.

\begin{tabular}{|c|c|c|}
\hline Virulence genes & Status & Gastritis, $n(\%)$ \\
\hline \multirow{2}{*}{$\operatorname{cag} A$} & Absent & $22(67)$ \\
\hline & Present & $11(33)$ \\
\hline \multirow{2}{*}{$\operatorname{vac} A m 1$} & Absent & $24(73)$ \\
\hline & Present & $9(27)$ \\
\hline \multirow{2}{*}{$v a c A m 2$} & Absent & $30(91)$ \\
\hline & Present & $3(9)$ \\
\hline \multirow{2}{*}{$\operatorname{vac} A s 1$} & Absent & $30(91)$ \\
\hline & Present & $3(9)$ \\
\hline \multirow{2}{*}{$v a c A s 2$} & Absent & $23(70)$ \\
\hline & Present & $10(30)$ \\
\hline \multirow{2}{*}{ ureA } & Absent & $9(27)$ \\
\hline & Present & $24(73)$ \\
\hline \multirow{2}{*}{ ureB } & Absent & $25(76)$ \\
\hline & Present & $8(24)$ \\
\hline \multirow{2}{*}{ napA } & Absent & $2(6)$ \\
\hline & Present & $31(94)$ \\
\hline \multirow{2}{*}{$d u p A$} & Absent & $33(100)$ \\
\hline & Present & $0(0)$ \\
\hline \multirow{2}{*}{ oipA } & Absent & $32(97)$ \\
\hline & Present & $1(3)$ \\
\hline \multirow{2}{*}{ hpaA } & Absent & $22(67)$ \\
\hline & Present & $11(33)$ \\
\hline
\end{tabular}

were found in $73 \%$ and $24 \%$ of all isolates. The analysis results of $H$. pylori virulence genes revealed a specific association between the $H$. pylori napA virulence gene and $H$. pylori-related gastritis. It was found that $94 \%$ of patients with gastritis were positive for the H. pylori napA gene that is one of the most important virulence factors and taking a role in bacterial colonization and gastric inflammation. $H$. pylori napA virulence gene behaves as an immune modulator, and it can induce the production of oxygen radicals by the neutrophils [17]. Also, this bacterial virulence factor stimulates neutrophils, monocytes, and dendritic cells to cause induction of interleukin-12 (IL-12), IL-23, and IL-8 expressions $[18,19]$.

To the best of our knowledge, no report has shown that the direct association of the $H$. pylori napA gene with $H$. pylori-induced gastritis. $H$. pylori napA virulence gene could serve as a biomarker for the development of diagnostic kits to foresee the evolution of $H$. pylori-associated gastritis. 
TABle 5: Association between $H$. pylori clarithromycin resistance and virulence genes.

\begin{tabular}{|c|c|c|c|c|c|c|c|c|c|}
\hline Virulence genes & Status & $\begin{array}{c}\text { Susceptible, } \\
n(\%)\end{array}$ & $\begin{array}{c}\text { Resistant, } \\
n(\%)\end{array}$ & $\begin{array}{c}p \\
\text { value }\end{array}$ & Virulence genes & Status & $\begin{array}{c}\text { Susceptible, } \\
n(\%)\end{array}$ & $\begin{array}{c}\text { Resistant, } \\
n(\%)\end{array}$ & $\begin{array}{c}p \\
\text { value }\end{array}$ \\
\hline \multirow{2}{*}{ oipA } & Absent & $20(100)$ & $12(92.31)$ & \multirow{2}{*}{0.9} & \multirow{2}{*}{ oipA } & Absent & $23(95.83)$ & $9(100)$ & \multirow{2}{*}{0.27} \\
\hline & Present & $0(0)$ & $1(7.69)$ & & & Present & $1(4.17)$ & $0(0)$ & \\
\hline \multirow{2}{*}{ hpaA } & Absent & $14(70)$ & $8(61.54)$ & \multirow{2}{*}{0.69} & \multirow{2}{*}{ hpaA } & Absent & $15(62.5)$ & $7(77.78)$ & \multirow{2}{*}{0.2} \\
\hline & Present & $6(30)$ & $5(38.46)$ & & & Present & $9(37.5)$ & $2(22.22)$ & \\
\hline \multirow{2}{*}{$n a p A$} & Absent & $1(5)$ & $1(7.69)$ & \multirow{2}{*}{0.38} & \multirow{2}{*}{$n a p A$} & Absent & $2(8.33)$ & $0(0)$ & \multirow{2}{*}{0,81} \\
\hline & Present & $19(95)$ & $12(92.31)$ & & & Present & $22(91.67)$ & $9(100)$ & \\
\hline \multirow{2}{*}{ ureB } & Absent & $15(75)$ & $10(76.92)$ & \multirow{2}{*}{0.45} & \multirow{2}{*}{ ureB } & Absent & $18(75)$ & $7(77.78)$ & \multirow{2}{*}{0.43} \\
\hline & Present & $5(25)$ & $3(23.08)$ & & & Present & $6(25)$ & $2(22.22)$ & \\
\hline \multirow{2}{*}{ ureA } & Absent & $5(25)$ & $4(30.77)$ & \multirow{2}{*}{0.36} & \multirow{2}{*}{ ureA } & Absent & $7(29.17)$ & $2(22.22)$ & \multirow{2}{*}{0.66} \\
\hline & Present & $15(75)$ & $9(69.23)$ & & & Present & $17(70.83)$ & $7(77.78)$ & \\
\hline \multirow{2}{*}{$\operatorname{cag} A$} & Absent & $13(65)$ & $9(69.23)$ & \multirow{2}{*}{0.4} & \multirow{2}{*}{$\operatorname{cag} A$} & Absent & $15(62.5)$ & $7(77.78)$ & \multirow{2}{*}{0.2} \\
\hline & Present & $7(35)$ & $4(30.77)$ & & & Present & $9(37.5)$ & $2(22.22)$ & \\
\hline \multirow{2}{*}{$v a c A s 1 / s 2$} & Absent & $11(55)$ & $9(69.23)$ & \multirow{2}{*}{0.21} & \multirow{2}{*}{$v a c A s 1 / s 2$} & Absent & $15(62.5)$ & $5(55.56)$ & \multirow{2}{*}{0.64} \\
\hline & Present & $9(45)$ & $4(30.77)$ & & & Present & $9(37.5)$ & $4(44.44)$ & \\
\hline \multirow{2}{*}{$v a c A s 2$} & Absent & $13(65)$ & $10(76.92)$ & \multirow{2}{*}{0.23} & \multirow{2}{*}{$v a c A s 2$} & Absent & $17(70.83)$ & $6(66.67)$ & \\
\hline & Present & $7(35)$ & $3(23.08)$ & & & Present & $7(29.17)$ & $3(33.33)$ & 0.59 \\
\hline & Absent & $18(90)$ & $12(92.31)$ & & & Absent & $22(91.67)$ & $8(88.89)$ & \\
\hline vacA s1 & Present & $2(10)$ & $1(7.69)$ & 0.41 & vacA $s 1$ & Present & $2(8.33)$ & $1(11.11)$ & 0.6 \\
\hline & Absent & $13(65)$ & $9(69.23)$ & & & Absent & $16(66.67)$ & $6(66.67)$ & \\
\hline vacA $m 1 / m 2$ & Present & $7(35)$ & $4(30.77)$ & 0.4 & vacA $\mathrm{m} 1 / \mathrm{m} 2$ & Present & $8(33.33)$ & $3(33.33)$ & 0.5 \\
\hline & Absent & $18(90)$ & $12(92.31)$ & & & Absent & $23(95.83)$ & $7(77.78)$ & \\
\hline$v a c A m 2$ & Present & $2(10)$ & $1(7.69)$ & 0.41 & & Present & $1(4.17)$ & $2(22.22)$ & 0.95 \\
\hline & Absent & $14(70)$ & $10(76.92)$ & & & Absent & $17(70.83)$ & $7(77.78)$ & \\
\hline$v a c A m 1$ & Present & $6(30)$ & $3(23.08)$ & 0.33 & $m 1$ & Present & $7(29.17)$ & $2(22.22)$ & 0,34 \\
\hline VacA $m 1$ Vact s? & Absent & $9(45)$ & $10(76.92)$ & $0.03^{*}$ & & Absent & $14(58.33)$ & $5(55.56)$ & \\
\hline 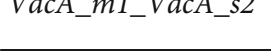 & Present & $11(55)$ & $3(23.08)$ & 0.03 & $V a c A \_m I_{-} V$ & Present & $10(41.67)$ & $4(44.44)$ & 0.56 \\
\hline
\end{tabular}

TABle 6: Association between $H$. pylori fluoroquinolone resistance and virulence genes.

denal ulcer development and reduced risk of gastric cancer. Due to our results, $d u p A$ virulence gene could be used as a specific biomarker for the detection of peptic ulcer diseases [22].

In the literature, some articles show the association between virulence factors and antibiotic resistance in $H$. pylori with controversial results. In one of the studies, the absence of $\operatorname{cag} A$ was correlated with metronidazole resistance [23] and in other studies vacA S1 and cagE are associated with clarithromycin and metronidazole resistance [24]. However, in some articles, it was found that neither vacA nor cagA correlates with resistance. In our present study, no statistically significant association was found between the vacA, cagA, oipA, babA, napA, hpaA, dupA, ureA, and ure $B$ virulence genes of $H$. pylori with the clarithromycin and fluoroquinolone resistance in $\mathrm{H}$. pylori-infected patients with gastritis. A major limitation of our work was a relatively low number of patients with specific clinical manifestations. Studies to be carried out by increasing the number and variety of patients may give more accurate results for the virulence factor and drug resistance relation and $H$. pylori virulence factors could be used to predict the clinical outcome as well as to determine antibiotic susceptibility. 
In conclusion, our current data showed that the analysis results of virulence genes expose a specific association between $H$. pylori napA virulence gene and clinical outcome; furthermore, no significant association could be detected among virulence genes and resistance or susceptibility. Also, the $\operatorname{dupA}$ gene was not found in any patient with gastritis that is thought to be one of the major markers for ulcer diseases. Our data results for the significant correlation between the $v a c A s 1 / \mathrm{m} 2$ and clarithromycin supports the literature information for the lack of vacuolating ability of $v a c A s 2$ variation. Despite advances in our understanding of the correlation between $H$. pylori virulence factor and clinical outcome with antibiotic resistance, it is necessary to carry out further investigations to learn more information about the relation between the $H$. pylori virulence genes and the antibiotic resistance and clarify the roles of $H$. pylori virulence factors.

\section{Data Availability}

The data in the article can be used with reference.

\section{Ethical Approval}

This study was approved by the ethics board of the Yeditepe University, Istanbul, Turkey (date of approval: January 2016).

\section{Conflicts of Interest}

The authors have no conflicts of interest to declare.

\section{References}

[1] M. Sirous, J. F. Mehrabadi, N. E. Daryani, S. Eshraghi, S. Hajikhani, and M. H. Shirazi, "Prevalence of antimicrobial resistance in Helicobacter pylori isolates from Iran," African Journal of Biotechnology, vol. 9, no. 36, pp. 5962-5965, 2011.

[2] L. Pacifico, C. Anania, J. F. Osborn, F. Ferraro, and C. Chiesa, "Consequences of Helicobacter pylori infection in children," World Journal of Gastroenterology, vol. 16, no. 41, pp. 51815194, 2010.

[3] A. Pilotto and M. Franceschi, "Helicobacter pylori infection in older people," World Journal of Gastroenterology, vol. 20, no. 21, pp. 6364-6373, 2014.

[4] S. Agudo, T. Alarcón, P. Urruzuno, M. J. Martínez, and M. López-Brea, "Detection of Helicobacter pylori and clarithromycin resistance in gastric biopsies of pediatric patients by using a commercially available real-time polymerase chain reaction after NucliSens semiautomated DNA extraction," Diagnostic Microbiology and Infectious Disease, vol. 67, no. 3, pp. 213-219, 2010.

[5] M. Guslandi, "Review article: alternative antibacterial agents for Helicobacter pylori eradication," Alimentary Pharmacology \& Therapeutics, vol. 15, no. 10, pp. 1543-1547, 2001.

[6] T. Uotani, M. Miftahussurur, and Y. Yamaoka, "Effect of bacterial and host factors on Helicobacter pylori eradication therapy," Expert Opinion on Therapeutic Targets, vol. 19, no. 12, pp. 1637-1650, 2015.

[7] J. F. Tomb, O. White, A. R. Kerlavage et al., "The complete genome sequence of the gastric pathogen Helicobacter pylori," Nature, vol. 388, no. 6642, pp. 539-547, 1997, Epub 1997/08/07.
[8] F. Sommer, G. Faller, P. Konturek et al., "Antrum- and corpus mucosa-infiltrating $\mathrm{CD} 4^{+}$lymphocytes in Helicobacter pyloriGastritis display a Th1 phenotype," Infection and immunity, vol. 66, no. 11, pp. 5543-5546, 1998.

[9] C. T. Wittwer, K. M. Ririe, R. V. Andrew, D. A. David, R. A. Gundry, and U. J. Balis, "The LightCycler" ${ }^{\mathrm{TM}}$ : a microvolume multisample fluorimeter with rapid temperature control," Biotechniques, vol. 22, no. 1, pp. 176-181, 1997.

[10] A. Ménard, A. Santos, F. Mégraud, and M. Oleastro, "PCRrestriction fragment length polymorphism can also detect point mutation A2142C in the 23S rRNA gene, associated with Helicobacter pylori resistance to clarithromycin," Antimicrobial Agents and Chemotherapy, vol. 46, no. 4, pp. 1156-1157, 2002.

[11] M. Oleastro, A. Ménard, A. Santos et al., "Real-time PCR assay for rapid and accurate detection of point mutations conferring resistance to clarithromycin in Helicobacter pylori," Journal of Clinical Microbiology, vol. 41, no. 1, pp. 397-402, 2003.

[12] S. Oktem-Okullu, A. Tiftikci, M. Saruc et al., "Multiplex-PCRbased screening and computational modeling of virulence factors and T-cell mediated immunity in Helicobacter pylori infections for accurate clinical diagnosis," PLoS One, vol. 10, no. 8, article e0136212, 2015.

[13] S. Chattopadhyay, R. Patra, T. Ramamurthy et al., "Multiplex PCR assay for rapid detection and genotyping of Helicobacter pylori directly from biopsy specimens," Journal of Clinical Microbiology, vol. 42, no. 6, pp. 2821-2824, 2004.

[14] Y. Yamaoka, T. Kodama, O. Gutierrez, J. G. Kim, K. Kashima, and D. Y. Graham, "Relationship between Helicobacter pylori iceA, cagA, and vacA status and clinical outcome: studies in four different countries," Journal of Clinical Microbiology, vol. 37, no. 7, pp. 2274-2279, 1999.

[15] S. Kumar, A. Kumar, and V. K. Dixit, "Direct detection and analysis of vacA genotypes and cagA gene of Helicobacter pylori from gastric biopsies by a novel multiplex polymerase chain reaction assay," Diagnostic Microbiology and Infectious Disease, vol. 62, no. 4, pp. 366-373, 2008.

[16] D. E. Brennan, C. Dowd, C. O’Morain, D. McNamara, and S. M. Smith, "Can bacterial virulence factors predict antibiotic resistantHelicobacter pyloriinfection?," World Journal of Gastroenterology, vol. 24, no. 9, pp. 971-981, 2018.

[17] D. J. Evans Jr., D. G. Evans, T. Takemura et al., "Characterization of a Helicobacter pylori neutrophil-activating protein," Infection and Immunity, vol. 63, no. 6, pp. 22132220, 1995.

[18] M. M. D'Elios, A. Amedei, A. Cappon, G. Del Prete, and M. de Bernard, "The neutrophil-activating protein of Helicobacter pylori (HP-NAP) as an immune-modulating agent," FEMS Immunology and Medical Microbiology, vol. 50, no. 2, pp. 157-164, 2007.

[19] M. de Bernard and M. M. D'Elios, "The immune-modulating activity of the Helicobacter pylori HP-NAP: friend or foe?," Toxicon, vol. 56, no. 7, pp. 1186-1192, 2010.

[20] S. L. Palframan, T. Kwok, and K. Gabriel, "Vacuolating cytotoxin A (VacA), a key toxin for helicobacter pylori pathogenesis," Frontiers in Cellular and Infection Microbiology, vol. 2, p. 92, 2012.

[21] J. L. Rhead, D. P. Letley, M. Mohammadi et al., "A new Helicobacter pylori vacuolating cytotoxin determinant, the intermediate region, is associated with gastric cancer," Gastroenterology, vol. 133, no. 3, pp. 926-936, 2007. 
[22] A. Talebi Bezmin Abadi and G. Perez-Perez, "Role of dupA in virulence of Helicobacter pylori," World Journal of Gastroenterology, vol. 22, no. 46, pp. 10118-10123, 2016.

[23] I. Taneike, A. Nami, A. O'Connor et al., "Analysis of drug resistance and virulence-factor genotype of Irish Helicobacter pylori strains: is there any relationship between resistance to metronidazole and cagA status?," Alimentary Pharmacology \& Therapeutics, vol. 30, no. 7, pp. 784-790, 2009.

[24] H. Karabiber, M. A. Selimoglu, B. Otlu, O. Yildirim, and A. Ozer, "Virulence factors and antibiotic resistance in children with Helicobacter pylori gastritis," Journal of Pediatric Gastroenterology and Nutrition, vol. 58, no. 5, pp. 608-612, 2014. 